\title{
SURGICAL RECONSTRUCTION OF PREHENSILE FUNCTION IN TETRAPLEGICS
}

\author{
By G. ZRUbecky, M.D. \\ Rehabilitations Centre of the Allgemeinen Unfall Versicherungsanstalt \\ Tobelbad, Austria
}

THERE is no doubt that the restoration of a prehensile function in tetraplegics has to be the central aim of treatment. In every case of cervical spinal injury-even in high lesions-it is possible to restore a functionally sufficient kind of prehension by means of orthopaedic-technical aids or by a surgical procedure. In fractures of the fourth cervical vertebra with complete loss of functions below C.4 the dominant hand is supplied with a combined myoelectric orthosis. In complete paralysis below C.6 a graded tri-digital pinch, formed by the tips of the thumb, index and middle finger, is restored on the dominant hand by means of a motor, or reciprocal orthosis.

In every case the power of prehension of the non-dominant hand can be improved and reinforced surgically. Bunell (1948), the pioneer for surgery of the hand, recommends the tenodesis of the flexor tendons of the first three fingers with the radius, combined with a tendon graft for opposing the thumb.

On this topic report Freehafer (1969), Nickel, Perry and Garrett (1963) as well as Lamb and Landry (1972). The last two mentioned have done 52 surgical procedures on the hand in II3 patients with 7I tendon-transplantations for restoration of a prehensile function in tetraplegics.

In general the surgical possibilities for reconstruction of a prehensile function in a patient with an injury of the cervical spine is not to be used to its full extent in many places. Of course, these injured learn typical trick movements, developing patterns of prehension. The author has named them, consequently to the primary and secondary patterns of prehension, as 'tertiary patterns of prehension'. By means of these tertiary patterns of prehension the disabled can perform a few activities themselves. Certainly, one can be satisfied following the motto: 'If you can't use one hand, use both hands'. However I cannot accept this rather negative attitude in the treatment of impairment of prehension in tetraplegics. In nonparaplegics all possibilities are made use of in order to restore the use of the injured hand or even one finger. This is done by means of tendon graft and arthroplasty, transplantations of skin and nerves, or by transplantations of artificial joints, though in these injured the other hand has its normal function. In tetraplegics, who depend much more on the function of their hands than non-paraplegics, little use of the possibilities of modern surgery of the hand is made. In patients with a cervical spinal injury, particularly, all methods of up-to-date hand surgery will have to be used in the future. In every case with a complete lesion below C.6 the act of prehension can be improved, correct indication for surgery and atraumatic technique presupposed.

Of course, a hand cannot be restored normally because the reconstruction of the paralysed intrinsic muscles would be necessary. Nevertheless the gross power of grip can be reinforced and improved significantly. 
The quotation by Bunnell (1948) 'Where there is nothing-there is little already much' is appropriate concerning surgery in tetraplegics.

I have developed a method of surgery which improves and reinforces the gross power of prehensile function in the weaker and clumsiest hand in each of 16 tetraplegics with complete lesion below C.6. The follow-up of these injured has proved that almost exclusively, they now use the operated hand for all activities of daily living.

(A film was shown at the meeting to illustrate the technique of surgery and the functional results thereof.)

\section{REFERENCES}

Bunnell, St. (1948). 'Surgery of the Hand', 2nd Ed. Philadelphia: J. B. Lippincott.

FREEHAFER, A. A. (1969). Care of the hand in cervical spinal cord injuries. Int. $\mathcal{F}$. Paraplegia, 7, I I8.

Lamb, D. W. \& Landry, R. M. (1972). The hand in quadriplegia. Int. F. Paraplegia, 9, 204.

Nickel, V. L., Perry, J. \& Garrett, A. L. (1963). F. Bone and $\mathcal{7}$. Surg., 45 A.

ZRUBECKY, G. (I97I). Mitteilung über die tertiären Greifformen der Tetraplegiker (Orthesen zur Wiederherstellung einer Greiffunktion). Arch. orthop. Unfall-chir. 70, I22-I35.

ZRUBECKY, G. (I97I). Die Rehabilitation traumatischer Querschnittlähmungen, Zeitschrift f. Orthop. und ihre Grenzgebiete, 109 Band, 4 Heft, 709-734.

ZRUBECKY, G. (1972). Operative und konservative Wiederherstellung einer Greifform von schlaff gelähmten Händen bei Halsmarkgeschädigten. Handchirurgie, Heft, 2.

ZRUBECKY, G. (1972). Ortheses for restoration of prehensile function in tetraplegics. The Hand. 